\title{
Benvenuto Samson zum 90. Geburtstag \\ (11. Juni 1977)
}

Diese Festgabe soll die herzliche Zuneigung der Gratulanten, deren Zahl um ein Mehrfaches größer als die der Beitragsverfasser ist, zum Ausdruck bringen.

Benvenuto Samson, den wir zum Eintritt in das zehnte Lebensjahrzehnt beglückwünschen, wird von vielen Menschen unterschiedlicher Generationen und Positionen gehört und geachtet. Sein Urteil wiegt ihnen schwer; es weckt die Lauen, hält die Heißsporne zurüdk und zwingt alle zum Nachdenken. Dies läßt sich nicht allein aus seinem erfolgreichen Lebensweg von Moskau über Dresden, Frankfurt und Europa in die Welt, nicht allein aus seinen Begegnungen mit bekannten Künstlern, Politikern, Industriellen und Juristen und auch nicht nur aus der Bevorzugung der Immaterialgüter erklären. Zwar sagen die Ereignisse und Daten, von denen in UFITA Bd. 49 (1967) und Bd. 64 (1972), in FILM UND RECHT Nr. 5/1967 und Nr. 5/1972 und in NJW 1972, 1179 die Rede war, sowie die Veröffentlichungen, die in dieser Festgabe genannt sind, Entscheidendes aus. Zwar hat die wechselvolle Geschichte Europas, mit der Samsons Schicksal durch schwere und befreiende Erlebnisse verflochten ist, die Kraft seines Urteils gefestigt. Das Besondere aber, das seine Worte und Gedanken in allen Zuhörern und Lesern weiterklingen läßt, ist etwas ganz Persönliches: Er hat sich dem Geschehen gewachsen gezeigt und dadurch Vertrauen erworben. Er ist jung geblieben, weil er auch die früheren Stufen seiner Lebenstreppe nicht vergessen hat und weil er bereit wäre, denselben Weg noch einmal zu gehen. Ohne den Frieden mit sich selbst hätte er nicht die Kraft, auch für andere zu wirken. Wenn wir ihn nach Erfahrungen aus und mit seinem Leben fragen, dann beschenkt er uns reich; wir hören dabei auch, daß er, wenn er noch einmal anzufangen hätte, wieder Jurist werden möchte und es wieder für richtig und wichtig halten würde, in allen Dingen Maß zu halten und nie etwas zu übertreiben. Hier zeigt er uns einen Schlüssel zu der von ihm praktizierten Lebenskunst, die ihn dem Kern der Dinge näher gebracht und ihn davor bewahrt hat, sich vom Wesentlichen $\mathrm{zu}$ entfernen und extrem und einseitig zu werden. Sein Stil - straff und konzentriert, unpathetisch, aber phantasiesprühend und spontan — läßt aufhorchen. Samson überschätzt und verachtet die Menschen nicht, er liebt sie und will ihnen helfen. Deshalb sind seine offenen und kritischen Bemerkungen nicht verletzend, sondern heilsam. Zu den Ubertreibungen, 
die er immer gemieden hat, gehören die Abhängigkeit von Dogmen und von sachfremden Einflüssen, die Weitschweifigkeit und die Langeweile, die Lauheit und der Fanatismus, die Gewalttätigkeit, der Formalismus, die Autoritätsgläubigkeit, die Unfehlbarkeit und die $\mathrm{Hu}$ morlosigkeit. Frei von Vorurteilen gegen das Jungsein, das er bei sich selber nie verdrängt und deshalb sich erhalten hat, gewinnt er Generation um Generation der Jugend; im aufgelockerten und elastischen Umgang mit seinen Kindern und seinen Schülern hat er sie dazu angestiftet, zwischen dem Bleibenden und dem Vergänglichen zu unterscheiden und der Hoffnung den Vorrang vor der Resignation zu geben. In einem Alter, in dem andere sich zur Ruhe setzen, begann er die Arbeit an der Frankfurter Universität; seitdem hat er mehr als ein Vierteljahrhundert lang in über 50 Semestern durch Vorlesungen, Seminare und Doktorandenbetreuung beispielhaft auf die Jugend eingewirkt.

Es ist kein Zufall, daß hier keine laudatio einer Vergangenheit zustandekam, sondern gegenwärtige Ausstrahlungskraft bezeugt wird. Benvenuto Samson, dem Superlative maßlos erscheinen, hat Unübertreffliches erreicht.

Wir wissen, daß er selbst alles ihm Gegebene als ein ganz seltenes Geschenk mit Dank annimmt und schließen uns diesem Dank mit vollem Herzen an. 